\title{
Global and quantum risks of extreme temperature fluctuations in Moscow
}

\author{
Zhanna Mogiljuk ${ }^{1}$, and Michael Hlystunov ${ }^{1, *}$ \\ ${ }^{1}$ Moscow State University of Civil Engineering, 129337 Yaroslavskoye Shosse 26, Moscow, Russia
}

\begin{abstract}
The article discusses topical problems of legal support for construction activities in relation to global climate change. Therefore, the results of high-resolution studies were treated. These studies tracked the pattern of fluctuation intensity changes of maximum and minimum temperatures in Moscow in the period of 1973 to 2009. The article highlights methodology elements for the statistical analysis of technical risks for implementing extreme temperature loads. A quantitative predictive risk assessment of extreme high and low temperatures and thawing risks for the entire life cycle of buildings are given. These estimates are intended to take account of the thermal loads on the ecological systems of urban areas as well as to design buildings and engineering systems that form microclimate of premises. The paper presents for the first time the obtained by the authors and previously unknown quantum regularities of the air temperature variations in the surface layer of the atmosphere. It also contains graphic materials for statistical studies of the fluctuation intensity evolution of maximum and minimum daily temperatures in the city of Moscow.
\end{abstract}

\section{Analysis of the regulatory framework for thermal loads accounting}

Global climate change in urban areas of the Earth for the last decade is under the scrutiny of the global scientific community as well as international and governmental environmental organizations [1-3].

Recent results of such studies, carried out by scientists from Pittsburgh, Madrid and Potsdam universities, allowed them to come to the conclusion that the heat waves, similar to what was observed in Russia in the summer of 2010, will cover areas four times larger in 30 years. And by the end of the XXI century it will expose $85 \%$ of the land. If there are no actions to be taken now, then in the second half of the XXI century the land area, that is exposed to abnormally high temperatures, will increase by about $1 \%$ a year. Even more extreme temperatures, which are now practically not observed by this time, will be noted in $60 \%$ of the land.

Global warming creates global problems in terms of adaptation and construction activities (ecological systems of urban areas and facilities) to new climatic realities over the deep perspective of urban planning [4-6].

\footnotetext{
*Corresponding author: mcxmgsu@mail.ru
} 
Currently observed fluctuation intensity evolution of maximum and minimum temperatures in almost all urban areas of the planet significantly increases the environmental risks of extreme temperatures exposure on the normal life of the townspeople and their health. [7].

For example, there is the development of a wide range of foreign building materials and technologies of indoor climate formation in the construction industry, the development of which was started and completed in the second half of the twentieth century when the problem of global climate change was not as relevant as today. [8].

The critical escalation of this problem relevance is reflected in the long periods of the preceding regulatory documentation validity and its forced modernization in response to global climate change. For example, SNiP 2.01.07-85 "Loads and impacts" have been applied without major changes and additions since 1985, for 26 years (until 2011), until the rulebook SP 20.13330.2011 [9] and SNiP 23-01-99* "Construction climatology" [10] came into effect, slightly taking into account the current climatic realities.

The main drawback of these papers $[9,10]$ is the lack of data, that take into account risks of the thermal loads adverse evolution (due to global climate change) on building structures and engineering systems, which form microclimate of premises for the upcoming period of the buildings operation.

At the same time the efficiency of technologies and engineering systems, that form microclimate of premises, significantly depends on the superdesign fluctuations in thermal loads that affect the processes intensity of heat and mass transfer and convection as well as thermal processes.

According to the rulebook, the temperature loads accounting for building and structure design is recommended to conduct with zoning maps of the Russian Federation on the average monthly air temperature in January and July, and also on deviations of the average air temperature at the coldest days of the average monthly temperature in January (maps 5,6 and 7 of Appendix $Ж$ of SP 20.13330.2011). The reliability coefficient for the load $\gamma_{f}$ for temperature climatic actions is recommended to be taken equal to 1.1 .

However, the recommended value of the parameter $\gamma_{f}$ does not take into account the actual intensity of global climate changes and observed global and quantum evolution patterns of temperature loads on building structures and engineering systems, which form microclimate of premises.

In this regard, this article presents the results of high-resolution statistical studies of the thermal processes evolution on the example of Moscow over the last 35 years. These studies were performed by the authors on the basis of the RSA`s Branch research laboratory in the framework of the M.Hlystunov's scientific school "Macroprofile of microcirculation, microvolts and effects".

In the future, these results will be used by the authors for the evolution predictive modelling of the thermal risks of an unacceptable drop in the efficiency of engineering systems, which form microclimate of premises over the urban planning depth (up to 100 years or more) and will be presented in the following series of articles on this issue.

\section{Methodology elements of statistical analysis}

The authors conducted statistical studies of the temperature extreme fluctuation intensity evolution in several cities on different continents and in different climatic zones.

We will consider the statistical analysis results of extreme temperature fluctuations evolution regularities in Moscow and the contradictions with the data of the corresponding normative documentation in order to illustrate these studies results.

In accordance with clause 13.2 and 13.4 of SP 20.13330.2011 "Loads and impacts" [9] the average daily outdoor temperature in warm and cold seasons and their deviations from 
average monthly temperatures according to cards 5,6 and 7 of Appendix $Ж$ should be taken into account in building and structure design.

However, in SP 20.13330.2011 risks are not subjected to accounting and are not reflected in the Russian Federation territory temperature zoning maps, which are associated with the implementation of these temperatures extreme values due to global climate change, for example, for the operating period of buildings (over 25 years) or over the urban planning period (up to 100 years or more).

Along with this, to date neither normative nor scientific literature does not provide research results and other information as well as methodological suggestions for solving this problem in practical terms.

Several different approaches are currently used to evaluate the risk. In the economy, the result of dividing the unwanted events probability by the amount of damage from its effects is usually taken as a measure of risk.

With this approach the risk measure, which includes natural disasters such as temperature for a given class of events, for example, the increase in the cost of heating or air conditioning of buildings internal spaces, is determined by the formula:

$$
\boldsymbol{R}=\boldsymbol{P} \times \boldsymbol{C},
$$

where $\mathrm{P}$ is the probability of an event and $\mathrm{C}$ is the amount of damage from a certain type of its effects. Full risk is defined as the sum of the risks for each type of consequences.

At superdesign thermal loads damage may occur not only in additional costs for air conditioning but in the form of accelerated deterioration of building structures and utility networks, which reduce the operational and technical characteristics of the building. Therefore, in general case it is more convenient to apply a measure used in technical risk analysis which typically boils down to estimating the probability of unwanted or dangerous events.

With technical approach risk measure $R$ is a dimensionless quantitative characterization of risk (from 0 to 1 ) which is defined by the frequency of occurrence that is the ratio of the actual number of dangerous events sale cases $n$ to the largest possible number of events $N$ over the considered period of time:

$$
R=\frac{n}{N}
$$

Using the measure definition according to the expression (2.9) technical assessment of thermal risks in buildings and structures can be produced, for example, according to the formula:

$$
R(t)=R_{\kappa p}+R_{o}=\frac{n\left(\Delta t_{\kappa p}\right)}{N}+\frac{n\left(t_{o}\right)}{N},
$$

where $R_{\kappa p}, n\left(\Delta t_{k p}\right), R_{o}, n\left(t_{o}\right)$ - respectively, the probability and the actual number of temperature superdesign deviation events $\left(\Delta t_{k p}\right)$ from the long-term average, probability and number of temperature superdesign transitions events through zero $\left(t_{o}\right)$, a maximum total number of such events $N$ over the considered period of time.

The first indicator $R_{k p}$ can be interpreted as the risk of hypothermia or overheating of the building. The second indicator is the risk of defrosting water systems or accelerated wear of engineering networks and building structures materials. 


\section{High-resolution statistical analysis of the thermal loads evolution in Moscow}

In this section we will not assess directly the risks for yourself and leave this task to professionals in fact in the risk areas. Therefore, we will carry out statistical analysis of the thermal processes evolution on the territory of Moscow over the period from 1972 to 2009.

As the underlying data array we use the meteorological observations data of maximum and minimum temperatures over the period from 01.01.1973 to 31.08.1987, but as an data array we take the data about the current state of climatic processes evolution similar meteorological observations data over the period from 01.01.1995 to 31.08.2009 after the fall of the Shoemaker-Levy`s comet on Jupiter.

Thus the duration of the analyzed evolutionary period in this case would be 36 years and the current period of evolution would be 21 years.

In fig. 1 there are presented the high-resolution statistical analysis results of the maximum daily temperature evolution in Moscow over the period from 01.01.1973 to 31.08.2009.

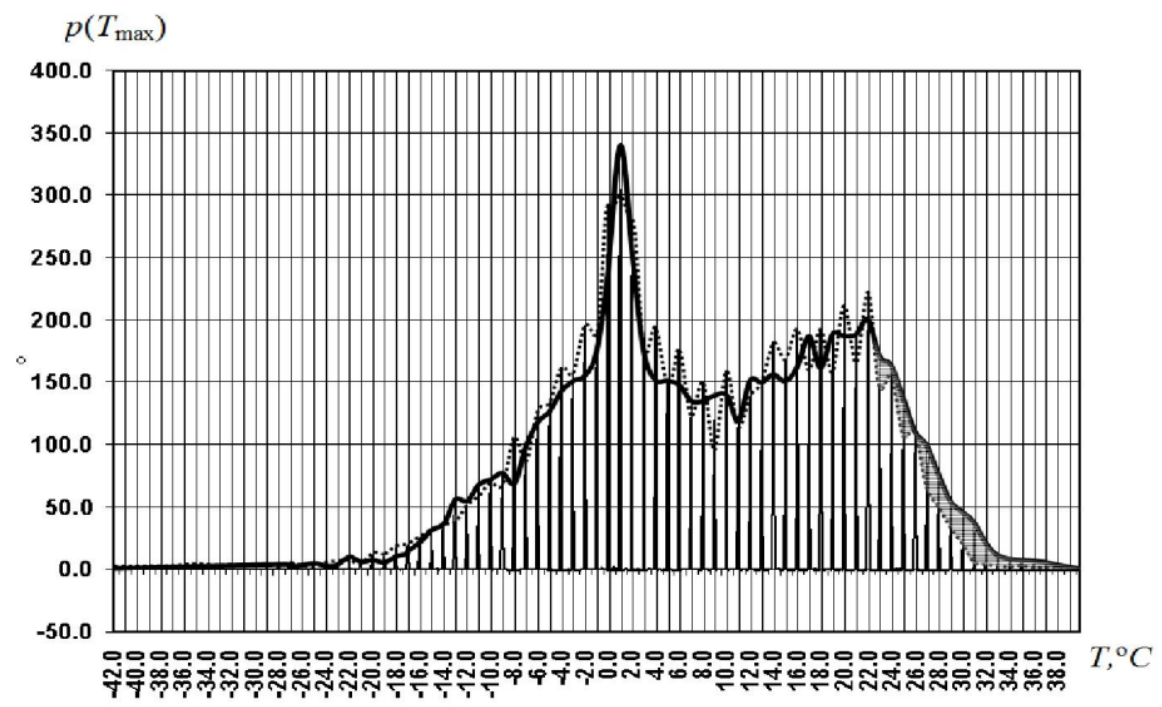

Fig.1. Distribution curves of density $p\left(T_{\max }\right)$ events of maximum daily temperatures implementation in Moscow: thin lines show statistical distribution curves of the maximum daily temperatures realization density; the dotted line is highlighted envelope curve which according to the period from 01.01.1973 to 31.08.1987; solid line represent the envelope curve which according to the period from 01.01.1995 to 31.08.2009; filling the selected area to increase the maximum temperatures realization density due to global climate change in the hottest period of the year

Comparative analysis of the maximum daily temperature evolution in Moscow (in Fig.1) confirms the manifestation of the global climate change process over the most hot (warm) period of the year (highlighted by shading).

The probability or technical risk of the temperature positive deviation over the 21 year range above $24^{\circ} \mathrm{C}$ rose by almost $17 \%$. The implementation risk of transitions through $0^{\circ} \mathrm{C}$ (thawing) rose more than 5\%.

Likewise the authors performed high-resolution statistical studies of the minimum daily temperatures evolution in Moscow over the period from 01.01.1973 to 31.08.2009, the 
results of which are shown in Fig.2.

Comparative analysis of the minimum daily temperatures evolution in Moscow (in Fig.2) also confirms the manifestation of the global climate change process both over the cold and warm (highlighted by shading) periods of the year.

The probability or technical risk of daily minimum temperature positive deviation in warm season over 21 years in the range above $+15^{\circ} \mathrm{C}$ increased by more than $15 \%$. The probability or technical risk of a minimum daily temperature negative deviation over 21 years in the range below $-29^{\circ} \mathrm{C}$ grew by no more than $10 \%$.

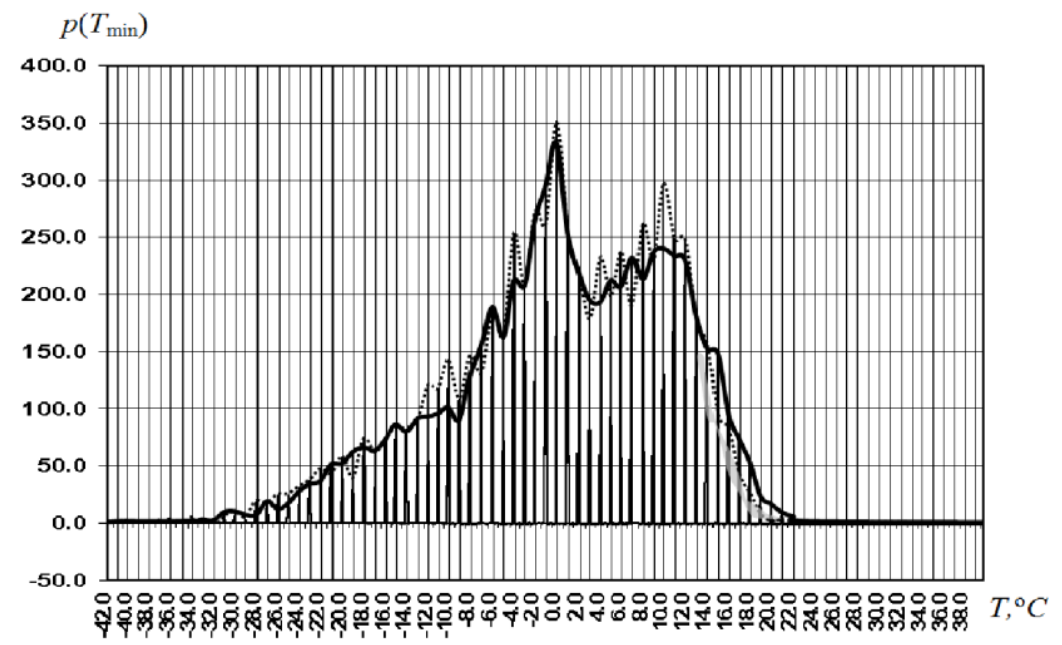

Fig. 2. Distribution curves of implementation events density $p\left(T_{\min }\right)$ of a minimum daily temperatures in Moscow: thin lines show the statistical distribution curves of the minimum daily temperatures density; the dotted line is highlighted envelope curve which according to the period from 01.01.1973 to 31.08.1987; solid line represent the envelope curve which according to the period from 01.01.1995 to 31.08.2009; fill the selected area represent increase of the minimum temperatures density due to global climate change in the warmest period of the year

Along with this in Fig.1 and in Fig. 2 there is the bar character of the density distribution curves of the maximum daily temperatures realization events (thin curves).

The nature of this curves indicates the quantum nature of the temperature change patterns which includes the implementation of the maximum and minimum daily temperatures.

This fundamental conclusion is confirmed by the authors' theory about the quantum nature of the air molecules motion momentum change process that was previously shown by the authors on the example of quantum regularities of the wind gusts formation [11-13]. This conclusion also fits into the framework of gases molecular-kinetic theory according to which the velocity of the gas molecules depends on its temperature.

Currently the authors prepare to publish a series of articles on the theoretical and experimental discovery of the quantum patterns of air temperature changes. These articles are based on the high-resolution statistical analysis of air temperature daily variations in New York, Moscow, London, Tokyo, Anchorage and Niamey reliably confirming the existence and manifestation of the quantum fundamental laws and the temperature fluctuations quantum nature in the surface layer of the Earth's atmosphere. 


\section{Conclusion}

The obtained results of statistical studies of the thermal loads evolution on buildings and engineering systems which forming microclimate of premises and environmental systems of urban territories allows to state the following.

The probability or technical risk of temperature positive deviations over the urban planning period ( $\sim 100$ years) during the warm period in the range above $24^{\circ} \mathrm{C}$ will increase to $81 \%$. The risk of transitions through $0^{\circ} \mathrm{C}$ (thawing) - up to $24 \%$.

The probability or technical risk of the minimum daily temperature positive deviations over the urban planning period ( $\sim 100$ years) in the range above $+15^{\circ} \mathrm{C}$ will increase to $71 \%$. The probability or technical risk of a minimum daily temperature negative deviation below $-29^{\circ} \mathrm{C}$ - up to $48 \%$.

In the research result was established for the first time previously unknown quantum pattern of temperatures variations (fluctuations) which was studied by the authors over range of temperatures (from $-40^{\circ} \mathrm{C}$ to $+40^{\circ} \mathrm{C}$ ). The fundamental nature of this discovery is confirmed by similar results that were obtained by the authors not only for Moscow but also for New York, London, Tokyo, Anchorage, Niamey and other cities on different continents.

The generalized results of the statistical analysis of temperature variations and the global climate change manifestations show that the greatest threat to buildings and engineering systems, which forms microclimate of premises, and environmental systems of urban territories is not only global climate change and general increase in temperature, but also the growth of variation intensity of daily and seasonal temperature processes.

For example, the minimum daily temperatures variance intensity over 21 years has changed by $1.25^{\circ} \mathrm{C}$ and the maximum by $2.6^{\circ} \mathrm{C}$ i.e. the oscillations amplitude has increased almost by $1.3^{\circ} \mathrm{C}$.

If this tendency will go on over the current period of urban planning ( $\sim 100$ years), so the risk of fluctuation intensity growth up to $6^{\circ} \mathrm{C}$ becomes plausible and at the same time increasing the probability of events occurrence exceeding the maximum temperatures over the multi-year level by $10^{\circ} \mathrm{C}$.

It is quite probable development of the global climate change process can not remain without attention of investors, self-regulatory organizations, owners of construction projects, property managers, energy companies, insurers and primarily municipal, regional and Federal services of regulation and urban planning activities.

This problem, both in Russia and abroad, is greatly exacerbated earlier not forecasted increase in the intensity of other dangerous technogenic and natural climatic and geophysical processes and factors that cause the implementation of new and as a consequence irregular superdesign loads and actions on buildings and engineering systems, which form microclimate of premises, and environmental systems of urbanized areas.

\section{References}

1. Managing the Risks of Extreme Events and Disasters to Advance Climate Change Adaptation Special Report (Cambridge University Press, London, 2012)

2. Climate Change 2013. The Physical Science Basis/Working Group I Contribution to the Fifth Assessment Report of the Intergovernmental Panel on Climate Change (Cambridge University Press, London, 2013)

3. V.I. Osipov. The Strategy journal of civil defense: problems and research, 2(2), 836846 (2012)

4. V. I. Telichenko, M.S. Khlystunov, V.I. Prokop'ev, J.G. Mogiluk, Vestnik MGSU, 2(2), 68-73 (2011) 
5. M.S. Hlystunov, V.V.Poduval 'tzev, J.G. Mogilyuk. Science and education, 11, (2011)

6. M.S. Hlystunov, V.V.Poduval 'tzev, V.I. Prokopiev \& J.G. Mogilyuk. Science and education, 12 (2011)

7. M.S. Hlystunov, V.V.Poduval'tzev, V.I. Prokopiev \& J.G. Mogilyuk. Science and education, 12 (2011) id: 77-30569/253299,

8. M.S. Hlystunov, V.I. Prokopiev \& Zh.G. Mogiljuk. Principles of the global evolution of the climatic loads and impacts. (MSUCE, Moscow, 2015)

9. Russian Standard SP 20.13330.2011.

10. Russian Standard SNiP 23-01-99*

11. M.S. Hlystunov, V.I. Prokopiev \& Zh.G. Mogiljuk. Life Science Journal 11(12s) 767-771 (2014)

12. M.S. Hlystunov, V.I. Prokopiev \& Zh.G. Mogiljuk. Modern Applied Science, 9(1), 96-102 (2015)

13. M.S. Hlystunov, V.I. Prokopiev \& Zh.G. Mogiljuk. Int. J. for Computational Civil and Structural Engineering, 10(2), 111-120 (2014) 